\title{
Do Pupils From Low-Income Families Get Low-Quality Teachers? Indirect Evidence from English Schools
}

\author{
Gaps between the educational attainment of pupils from higher and lower income families are \\ widespread and persistent. Teacher quality is amongst the most important school-based \\ determinants of pupil attainment, making the allocation of teachers to pupils a potentially \\ important reason for this attainment gap. We use a range of well-evidenced indicators of teacher \\ quality from the School Workforce Census and the Teaching and Learning International Survey to \\ investigate the extent of social inequalities in access to teacher quality in England. Looking at the \\ allocation of teachers between schools, we find that disadvantaged pupils are more likely to have \\ unqualified, inexperienced or out-of-subject teachers. We present evidence that this reflects both \\ demand from early-career teachers to work in such schools and a greater supply of vacant \\ positions in these schools, due to poor staff retention. We find some evidence of an inequitable \\ allocation of teacher quality to classes within schools, though this is limited to our teacher \\ experience indicator. This is in part due to teachers with more experience at a specific school being \\ better able to influence their allocation to less disadvantaged classes. Implications for policy are \\ discussed.
}

Keywords: teachers; teacher allocation; attainment gaps; organisational capital

\section{Introduction}

\section{The Persistence of Inequalities in Educational Attainment}

Inequalities in educational attainment by family background are found across the developed world (OECD, 2012). Across nations, the gaps are substantial, with disadvantaged pupils' reading ability falling behind their most affluent peers by between one and three years of schooling by the end of secondary education (Jerrim, 2012). These gaps are also persistent, remaining broadly stable across the OECD between 2000 and 2009 (Jerrim, 2012). In England, the context for this study, the patterns are similar. At age 11, pupils entitled to free school meals (FSM) are around half as likely to achieve a Level 5 or above in English and Maths than their more affluent peers (Strand, 2014). At age 16, FSM pupils are again around half as likely to achieve five good GCSEs (between $A^{*}$ and C) including English and Maths (Lupton and Thompson, 2015). While the gap between FSM and Non-FSM pupils declined in the second half of the twentieth century (Blanden and MacMillan, 2014), the gap between the top and bottom income quintiles remained high and broadly stable over that period (Macmillan and Gregg, 2007).

These inequalities have persisted despite a range of policies aimed at narrowing the gap. In England, disadvantaged pupils attend less effective schools (Hobbs, 2016). The reasons for this are complicated, with family resources and support for education, school organisational structures and climate all playing a role (Thrupp and Lupton, 2006). A number of policies have therefore been implemented with the aim of improving disadvantaged 
pupils' access to better schools. The Assisted Places Scheme (1980), for example, provided subsidised private education for low-income, high-ability students. Later that decade, the Education Reform Act (1988) allowed pupils to express a preference for which school they attended. A number of policies have also tried to improve the schools which disadvantaged pupils attend. The introduction of Office for Standards in Education (Ofsted), collaborative programmes such as the London Challenge, and the increase in resources going in to schools serving disadvantaged intakes through the Pupil Premium are all examples of this approach. While these policies may have contributed to narrowing the gap however, they have failed to eliminate it. Moreover, progress seems to have slowed in recent years (Lupton and Thompson, 2015).

One plausible explanation for this is that policy is not targeting the most important causes of the gap. Reviews of research consistently show that teacher quality is amongst the most powerful school-based determinants of pupil attainment (Burgess, 2015; Hanushek and Rivkin, 2012), with the effects of access to higher quality teachers detectible in adult earnings over a decade after leaving school (Chetty et al., 2014). Moreover, because high quality teachers have been shown to have a disproportionately large effect on the progress of disadvantaged pupils (Aaronson et al., 2007; Slater et al., 2012) this could also narrow gaps within classrooms. In short, while policies focusing on choice, accountability, collaboration and funding may contribute to closing the gap, they may be missing the point of greatest leverage: teacher allocation.

\section{Existing Literature on Teacher Allocations}

This raises the question of whether students from different social backgrounds do indeed have unequal exposure to high quality teachers. A number of studies in the US find that schools with more disadvantaged intakes generally have less qualified teaching staff (Clotfelter et al., 2007; Feng, 2010; OECD, 2014), including one study in the UK (Allen et al., 2017). Four studies, all from the US, go a step further by measuring the allocation of teacher quality based on pupil test score gains. Sass et al. (2010), Isenberg et al. (2013) and Mansfield (2015) find evidence of a small bias in the allocation of high quality teachers towards schools serving more advantaged pupils. Baird et al. (2016) find no overall inequalities in the allocation of teacher quality, though this varies in the different districts in their sample.

Research looking at the allocation of teachers to classrooms within schools have a clearer set of results. Studies using a range of datasets, all from the US, have found that classes containing disadvantaged pupil are more likely to get inexperienced or less qualified teachers (Grissom et al., 2015; Kalogrides et al., 2012; Loeb et al., 2012; Mansfield, 2015). Sass et al. (2010) look directly at the impact of individual teachers on pupils test score gains and find that higher quality teachers are assigned to classrooms with fewer disadvantaged pupils. Isenberg $e t$ al. (2013) and Mansfield (2015) replicate this finding but also point out that inequalities in allocation between schools are greater than within schools.

In summary, the existing literature suggests that there are important inequalities in the allocation of teachers to pupils both between and within schools. However, findings vary greatly from one school district to another (Baird et al., 2016; Isenberg et al., 2013; Sass et al., 2010), suggesting that local institutional or labour 
market differences may have an important impact. To our knowledge, the present study provides the first evidence from outside the US on social inequalities in access to teacher quality both between and within schools.

\section{Measuring Teacher Quality}

The US research described above generally uses data that allows teachers to be linked to the pupils they teach. Provided these teachers can be identified in multiple school settings, or (even better) be randomly allocated to classrooms, the contribution of individual teachers to pupil progress can be measured (McCaffrey et al., 2009; Kane et al., 2013). In the UK however, it is not possible observe which pupils are taught by which teachers using administrative data, making it hard to measure inequalities in access to effective teachers in the same way. For this reason, our approach is more akin to the studies by Clotfelter et al. (2007), Feng (2010), Grissom et al. (2015), Kalogrides et al. (2012) and Loeb et al. (2012) in that we look instead at observable indicators of teacher quality, rather than direct measures of teacher effectiveness. This section introduces the three indicators used and reviews the evidence for their association with pupil progress, emphasising where the results have been replicated in different datasets to demonstrate their robustness.

The first indicator of teacher quality that has been linked with lower teacher value added is whether or not a teacher is fully qualified/licensed. Goldhaber and Brewer (2000) were amongst the first to report this finding using the 1988 National Educational Longitudinal Study. Two papers using data on North Carolina schools, and a number of different specifications, have found that teachers without a full license are less effective (Clotfelter et al., 2006; Clotfelter et al., 2007). Kane et al (2008) and Boyd et al. (2008) use New York City data and also find that unlicensed teachers are less effective, though this result is not robust to all specifications in the former paper. The literature is not entirely consensual however, with Croninger et al (2007) finding no effect of certification status on attainment in their study of kindergarten children in the Early Childhood Longitudinal Study. This suggests that certification may be more important for secondary school teachers. We therefore analyse primary and secondary teachers separately in this paper.

The second indicator of teacher quality that we use is amount of experience on the job. The inferiority of newly qualified teachers has been replicated in a number of papers using data from Florida (Chingos and Peterson, 2011), North Carolina (Henry et al., 2011; Clotfelter et al., 2007), New York (Boyd et al., 2008) as well as the Early Childhood Longitudinal Study (Croninger et al., 2007). Until recently, the consensus was that the returns from experience trail off after around three years in the job. However, three recent papers using superior methodology have shown that the returns to experience actually continue much later into a teachers' career, up to and beyond ten years in the classroom (Harris and Sass, 2011; Wiswall, 2013; Papay and Kraft, 2015).

The third indicator of teacher quality measures how much teachers in the school are working outside of the subject in which they have been trained. Wayne and Youngs (2003, p107) reviewed early work in this area and concluded that the research was inconclusive "except in mathematics, where high school students clearly learn more from teachers with certification in mathematics, degrees related to mathematics and coursework related to mathematics." Since then a number of studies have replicated this finding using different datasets (Baumert et al., 
2010; Hill et al., 2010; Kane et al., 2008). Harris and Sass (2011) fail to replicate these findings using data from Florida but, as the authors state, this may be due to the small sample size. Outside of mathematics, it is less clear that subject-specific training matters (Goe, 2007). We therefore provide separate results by maths/non-maths in this paper. These indicators allow us to study the allocation of teacher quality in English schools.

\section{The Allocation of Teacher Quality Between Schools}

\section{Data and Method}

Data for our between-school analysis are taken from the School Workforce Census (SWC). This is a large administrative dataset which contains demographic, employment, absence, curriculum and qualification data on all teachers working in English state schools since 2010/11. At the time of writing, the most recent year for which data was available was 2014/15. The SWC includes a dummy variable indicating whether a teacher has qualified teacher status, which allows us to measure our first indicator of teacher quality. The SWC also contains the date when teachers first qualified, which we use to construct a measure of classroom experience. Unfortunately, we cannot observe whether teachers have taken a break from teaching and then returned to the classroom prior to 2010, making this an imperfect measure. Our third indicator can be observed in the SWC by looking at each timetabled hour in a subject and identify whether the teacher has an academic degree in the subject (see Allen, 2017, for further notes on how this is calculated).

In order to compare the allocation of teacher quality across schools we construct a deprivation measure for each school using the proportion of pupils who qualify for free school meals (for a discussion of the use of FSM as a measure of deprivation, see Hobbs and Vignoles (2010)). Schools are then split into five equally sized groups based on this metric, with quintile 1 containing the $20 \%$ of schools with the least deprived intakes and quintile 5 containing the $20 \%$ of schools with the most deprived intakes.

\section{Findings}

Figure 1 shows the incidence of unqualified, low experience and high experience teachers, broken down by primary and secondary school phase. The proportion of teachers who are not qualified in primary schools with the highest concentration of FSM pupils is $4 \%$, while in schools with the least deprived intake the figure is $2 \%$. The gradient is similar for secondary, where schools with the least deprived intake have $5 \%$ unqualified teachers and those with the most deprived intakes have $9 \%$. The least deprived schools also have more highly experienced teachers. The lowest deprivation primary schools have $12 \%$ of teachers with more than ten years of experience while the most deprived schools have just $7 \%$. Among secondary schools the figures are $12 \%$ and $8 \%$ respectively. The gradients are present across primary and secondary school phases, meaning that the finding of unequal allocation 
does not depend on a point of interpretation about whether the existing literature shows effects at secondary stage.

\section{$<$ Figure 1 about Here>}

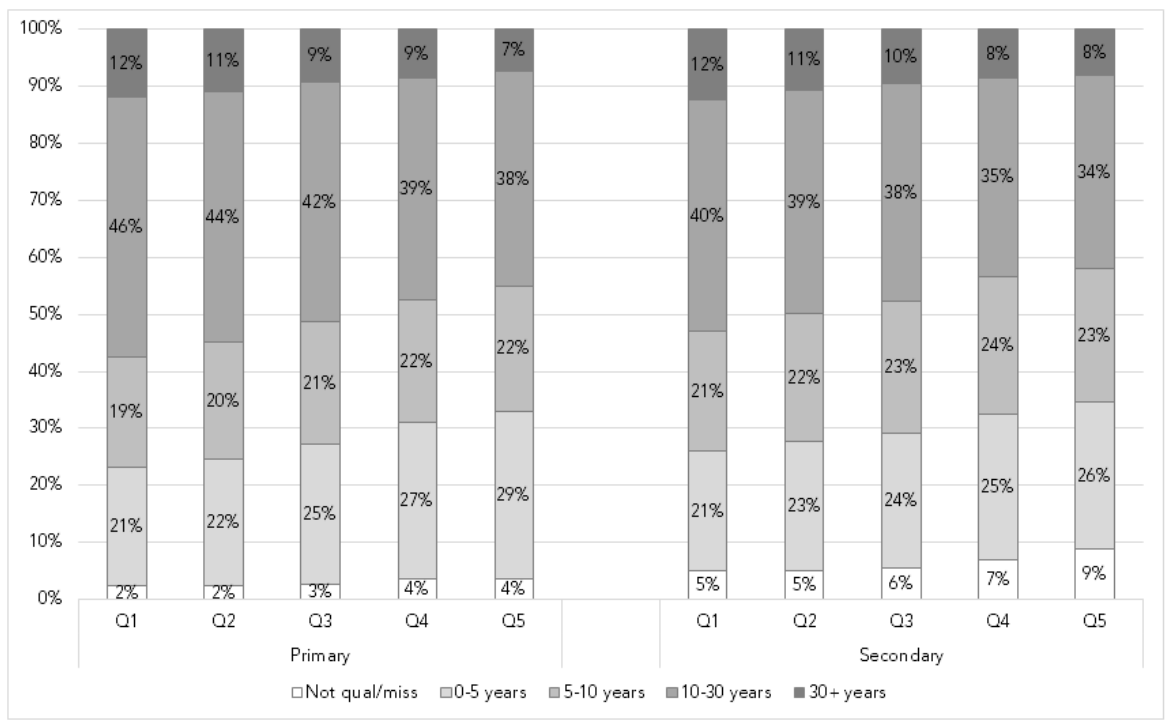

Inequalities in access to teacher quality are also visible when looking at whether teachers have a degree in the subject they are teaching. Figure 2 shows whether Key Stage 3 (KS3) teachers (those working with lower secondary schools pupils between 11 and 14 years of age) have an academic degree in the subject they are teaching across the five deprivation quintiles. Figure 3 shows the same for KS4 teachers (working with secondary school pupils aged 14 to 16). The results show a clear division between arts and science subjects. In both Key Stages, English, History, Geography and Modern Foreign Languages teachers are just as likely to have an appropriate degree across the deprivation quintiles. However, for Maths and Science subjects a clear gradient emerges, with more deprived schools much more likely to have teachers with inappropriate qualifications. For maths, which is our primary indicator of interest, the gap between the least and most deprived quintiles is 10 percentage points. Other subjects also have substantial gaps: 14 percentage points for KS4 Chemistry and 22 percentage points for Physics. It is interesting to note that the subjects with the biggest gaps are those for which teacher shortages are the most severe (NAO, 2016). This suggests that schools struggling to recruit are more likely to have to settle for teachers who have not studied the subject at degree level. 


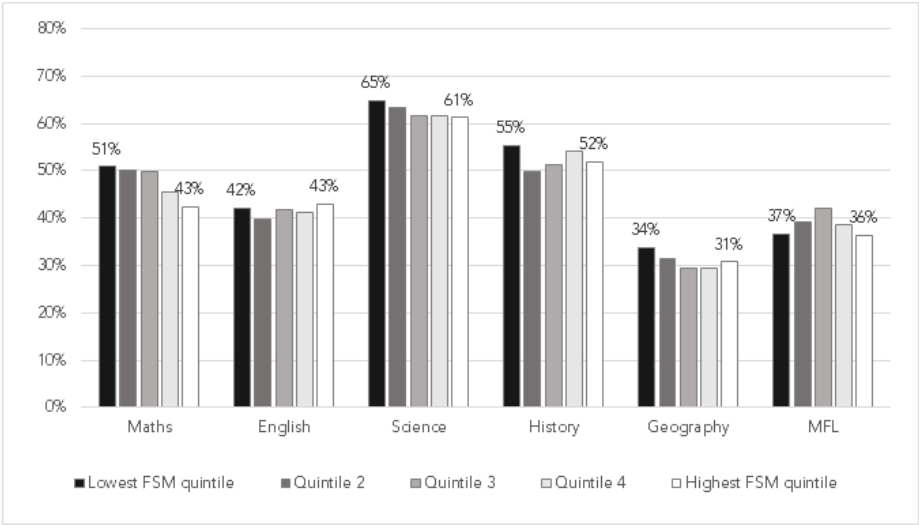

$<$ Figure 3 about Here $>$

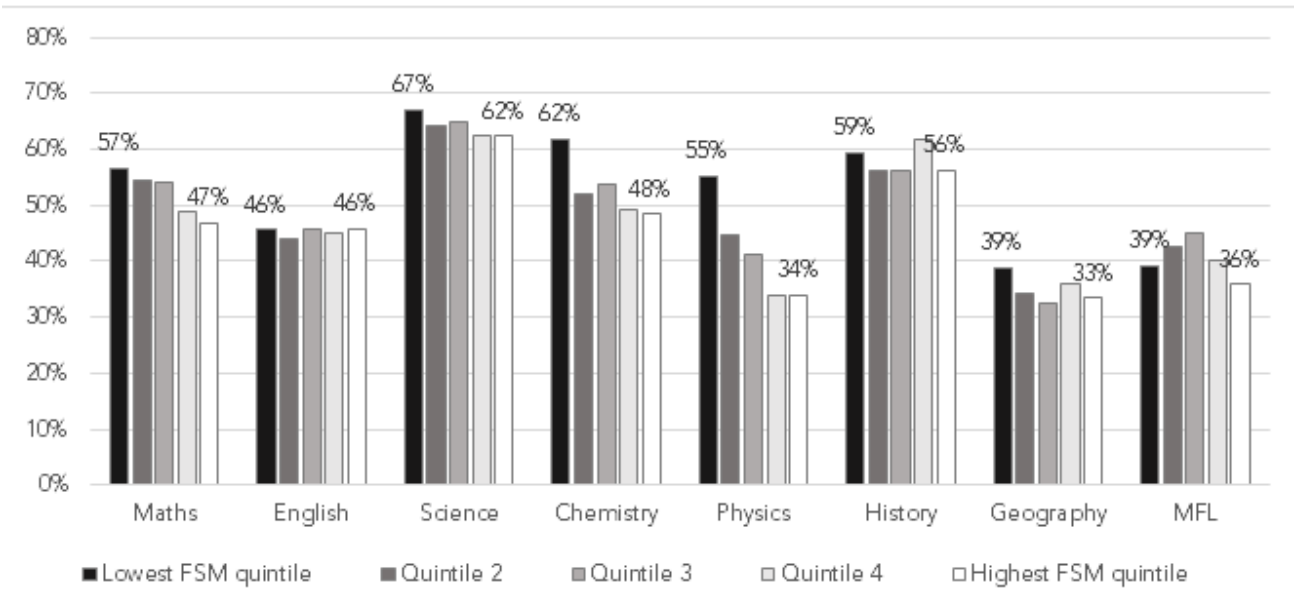

In summary, across all three of our indicators disadvantaged pupils are disproportionately likely to get lower quality teachers. Focusing for simplicity on secondary: the odds of pupils in the most deprived quintile of schools getting an unqualified teacher are $88 \%$ higher than those in the least deprived quintile; the odds of pupils in the most deprived quintile getting a novice teacher are $32 \%$ higher than those in the least deprived quintile; and the odds of those in the most deprived quintile getting an out of subject teacher are $49 \%$ higher than those in the least deprived quintile. Given the importance of teacher quality for child attainment and later earnings, these inequalities could well have materially important effects on life chances and later income inequalities. Of course it may be the case that, within schools, the most disadvantaged pupils are given access to the best quality teachers, mitigating the effects of these between schools allocation patterns. Before moving on to 
discuss such within school allocation however, we first discuss why these between-school inequalities occur.

\section{Explaining unequal allocation of teaching quality between schools}

Any explanation of these teacher allocation patterns must first account for the reasons that inexperienced, unqualified or out-of-subject teachers join particular schools. Many early-career teachers find positions in schools serving disadvantaged intakes (Allen et al., 2012). In part, this likely reflects the preferences of teachers. For example, a recent survey found that the reason most frequently cited by early-career teacher's for joining the profession was "making a difference to pupils lives", which was identified as a "very important" reason by $60 \%$ of respondents, with a further $45 \%$ citing the "opportunity to make a difference to society" as being very important (Menzies et al. 2013). This demand-side effect is reinforced on the supply side by the higher number of vacancies available in schools with more disadvantaged pupils. Our data show that annual turnover (defined as the proportion of teachers who are working in a school in year t but are no longer working there in year $t+1$ ) in schools in the most deprived quintile is $58 \%$ higher than those in the least deprived quintile. This turnover creates vacancies which means that there are plenty of job opportunities in these schools for early-career teachers. Surveys of head teachers have shown that schools facing many vacancies tend to react by lowering recruitment standards (Smithers and Robinson, 2000) which may also explain why head teachers are more likely to appoint out-of-subject teachers (Figure 3). Early-career (inexperienced, pre-qualification) teachers are therefore both willing to work in disadvantaged schools and, along with out-of-subject teachers, find it easier to get work in them. Taken together, this evidence provides an explanation for the concentration of low quality teachers entering disadvantaged schools.

The flip side of explaining teacher allocation is understanding why teachers leave certain schools. The survey by Menzies et al. (2013) also asked teachers about their motivations for staying in the profession. Although "changing pupils' lives" remained an important reason, the most frequently cited reason for staying is "Being good at it" (84\%). This survey evidence is corroborated by a range of controlled studies showing that teachers are more likely to quit if they feel they are not becoming good teachers (Klassen and Chui, 2011; Johnson and Birkeland, 2003; McNatt and Judge, 2008). A number of studies (for a review, see Simon and Johnson, 2013) have shown that schools with disadvantaged intakes are generally less supportive working environments for teachers. We investigate whether this greater workforce instability can be explained by local labour market conditions and teacher characteristics alone, or whether schools with disadvantaged intakes have some additional turnover that might signal more difficult teaching environments. We do this by using four logistic regressions to model the chances that a teacher leaves their school in summer 2013, adding explanatory variables in turn. The first estimates the odds of leaving based school FSM quintile alone. The second adds to this a vector of teacher individual characteristics: age, gender, ethnic minority status, qualified status, experience. The third also adds a vector of region dummies to account for the wider teacher labour market conditions in that region. Finally, we replace the regional dummies with a random effect that accounts for underlying teacher labour market conditions at the more localised area of a parliamentary constituency. The full model is set out in the Appendix. 
Figure 4 shows that in primary schools, when no control variables are used in the model, the odds of a teacher leaving a school are $20 \%$ higher in the most deprived than in the least deprived quintile of schools. Expressed as turnover rates, this equates to $17 \%$ in the least deprived schools and $21 \%$ in the most deprived schools. Controlling first for a set of teacher characteristics and then for the region and parliamentary constituency in which the school is located does not attenuate the relationship between disadvantage and turnover. At secondary level (Figure 5) the relationship is even stronger. When controls are used in the model, the odds of a teacher leaving a school are $60 \%$ higher in the most deprived than in the least deprived quintile of schools. Expressed as turnover rates, this equates to $16 \%$ in the least deprived schools and $23 \%$ in the most deprived schools. Differences in the odds of teachers leaving are even more pronounced if we compare schools with different levels of deprivation that are located in the same local area (i.e. parliamentary constituency). Teach First deliberately places inexperienced teachers in more deprived schools and has a low retention rate, meaning it will contribute to these inequalities. However Teacher First is only responsible for around one-sixth of the observed gradient, because it only accounts for a small proportion of initial teacher training (Allen et al., 2016). This sort of high turnover, even after accounting for teacher characteristics and school location, can further damage social support networks in schools. This can make it hard for more deprived schools to provide adequate support for new teachers, which can further perpetuate the cycle of high turnover (Feng, 2010).

\section{$<$ Figure 4 about Here $>$}

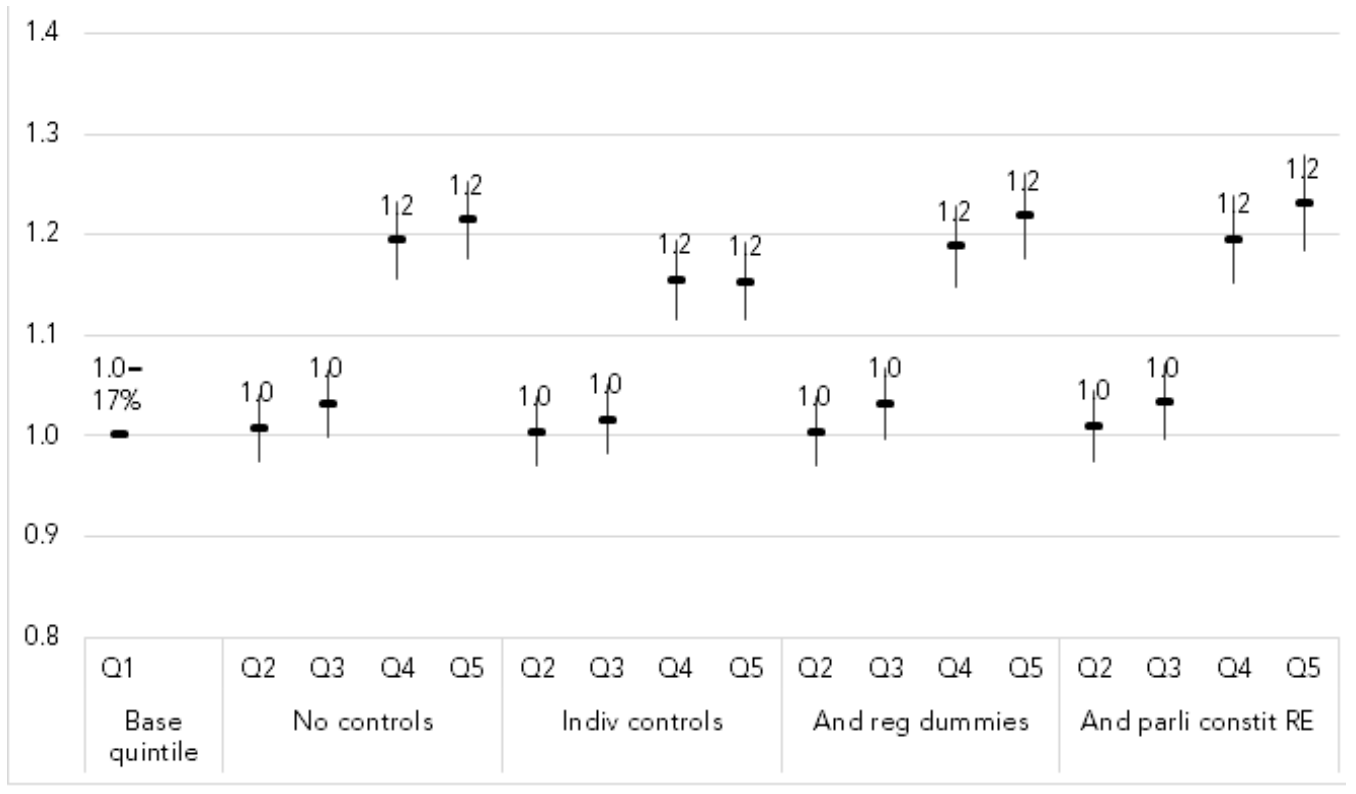

$<$ Figure 5 about Here> 


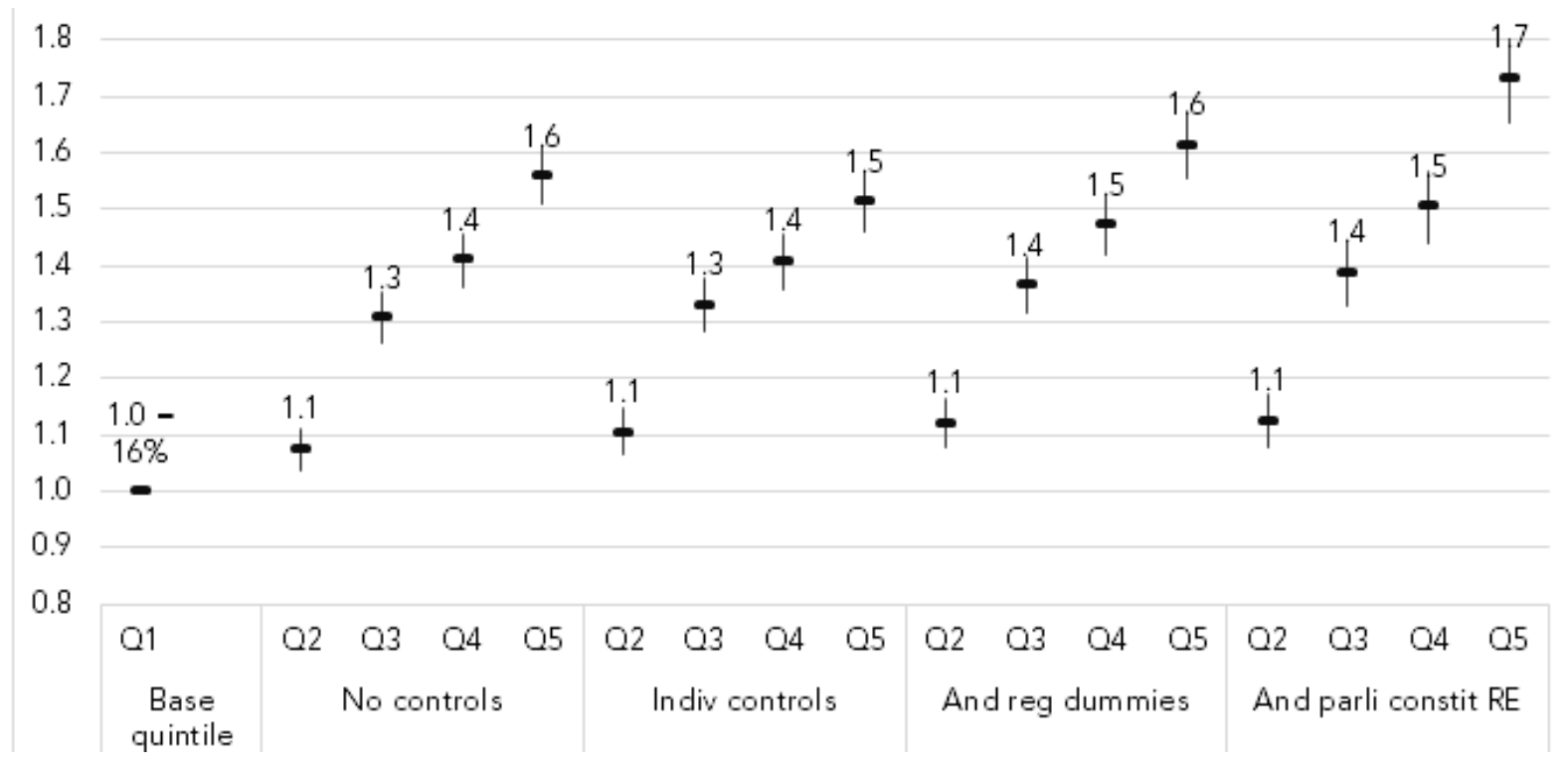

\section{The Allocation of Teacher Quality Within Schools}

\section{Data and Method}

The SWC does not allow us to assess the distribution of teacher quality within schools because the only information it provides on teaching assignments is the subject and year groups that are taught. For the within-school analysis we therefore use data from the Teaching and Learning International Survey (TALIS) 2013. TALIS was first conducted in 2008 and occurs every five years. In 2013, data were collected from 34 different countries or regions around the world. Within each country at least 200 schools were randomly sampled, with $20 \mathrm{KS} 3$ teachers from each school randomly selected to respond to the survey. In 2013 2,496 teachers from 154 schools in England responded, representing a school response rate of $75.1 \%$ and a teacher response rate of $83.4 \%$ (Micklewright, 2014).

TALIS collects information on all aspects of teachers and their working lives including their background, the professional development available to them, feedback, pedagogy and school climate. Crucially for our purposes, TALIS asks respondents to provide information about a specific "target class", which is defined as the class they were teaching at 11 am last Tuesday (or the first subsequent KS3 class). Clearly, this is only one of many classes that the responding teacher will work with. But there are two ways in which we can be confident that it is representative. First, the Tuesday 11am criteria is arbitrary and therefore the class that a teacher works with at that time is plausibly exogenous to the make-up of that class. Some sampled teachers will have a target class that is more disadvantaged than their average class and some sampled teachers will have a target class that is less disadvantaged than their average class. Across the 2,496 teachers that responded however, these differences should balance each other out. Second, the respondents are asked whether the target class is representative of all the classes they teach. We therefore report robustness tests in which we check whether the results hold for the sub-group of teachers who say their target class is representative.

Ideally, we would use objective measures of pupil deprivation as in the between-school analysis. Unfortunately, such a measure is not available in the TALIS dataset. However, teachers are 
asked to estimate the proportion of pupils in their target class who qualify for free school meals and record the answer on the following scale: $0 \% ; 1-10 \% ; 11-30 \% ; 31-60 \%$; more than $60 \%$. For this stage of the analysis we therefore use ordered logit regression to assess whether the estimated proportion of disadvantaged pupils in a classroom is related to each of our indicators of teacher effectiveness in turn. Coefficients are reported as odds ratios, so a coefficient of $1.2(0.8)$ means a one unit increase in our indictors of teacher effectiveness correspond to a $20 \%$ increase (decrease) in the odds of the target class being one deprivation category higher. We control for the school in which the teacher works, so that we are comparing within schools, but we do not control for other factors because we are checking for an association (whether disadvantaged kids are more likely to experience ineffective teachers) rather than trying to model the determinants of an outcome. If the confidence interval includes an odds ratio of 1 then our results are compatible with there being no association at the $95 \%$ confidence level. This is effectively equivalent to a t-test, but using regression allows us to account for the complex survey design used in the TALIS questionnaire in order to correctly estimate the standard errors. This is done using the REPEST programme in STATA (Avvisati and Keslair, 2015).

\section{Findings}

Our within-school analysis shows less consistent evidence of inequality in access to teacher quality. The relationship between whether a teacher is qualified and how disadvantaged their class is does not reach statistical significance at conventional levels. Years of experience shows an association, statistically significant at the $99 \%$ confidence level, and this is robust to a narrowing of the sample to teachers who reported their target class being representative of their other classes. Each additional year of experience is associated with a $2 \%$ decrease in the odds of having a target class falling in a higher deprivation category, increasing to $3 \%$ amongst teachers who report their target class being representative. Predictive margins show that the probability a teacher with mean characteristics and one year of experience has a target class with less than $10 \%$ of disadvantaged pupils is $43.9 \%$, whereas for a teacher with ten years of experience, the probability is $48.6 \%$. Our third indicator of teacher quality - subject specialism - also fails to reach statistical significance at conventional levels. In results not shown for space reasons, we also establish that there is no association when look specifically at maths and science teachers. In summary, we find some evidence that less less effective teachers are given classes with more disadvantaged pupils, although this is limited to our experience indicator.

<Table 1 about Here> 


\begin{tabular}{|c|c|c|c|}
\hline & & Full Sample & $\begin{array}{c}\text { Representative } \\
\text { target classes }\end{array}$ \\
\hline \multirow{4}{*}{$\begin{array}{l}\text { Qualified } \\
\text { teacher status }\end{array}$} & Odds ratio & 1.31 & 1.27 \\
\hline & Standard error & $(0.244)$ & $(0.425)$ \\
\hline & $95 \%$ confidence interval & $0.832-1.789$ & $0.434-2.10$ \\
\hline & $\mathrm{N}$ & 2,330 & 1,584 \\
\hline \multirow{4}{*}{$\begin{array}{l}\text { Years of } \\
\text { experience in } \\
\text { teaching }\end{array}$} & Odds ratio & $0.98 * * *$ & $0.971 * * *$ \\
\hline & Standard error & $(0.00685)$ & $(0.00815)$ \\
\hline & $95 \%$ confidence interval & $0.967-0.994$ & $0.954-0.986$ \\
\hline & $\mathrm{N}$ & 2,314 & 1,506 \\
\hline \multirow{4}{*}{$\begin{array}{l}\text { No bachelors } \\
\text { in subject } \\
\text { taught }\end{array}$} & Odds ratio & 0.865 & 1.034 \\
\hline & Standard error & $(0.115)$ & $(0.163)$ \\
\hline & $95 \%$ confidence interval & $0.64-1.0902$ & $0.714-1.35$ \\
\hline & $\mathrm{N}$ & 2,336 & 1,506 \\
\hline
\end{tabular}

\section{Explaining unequal allocation of teaching quality between schools}

Discussion of the mechanisms underpinning teacher allocation can help shed light on these findings. Early qualitative research in this area (Finley, 1984; Monk, 1987) suggested that more experienced teachers use their influence in the school to acquire desirable class allocations. More recently, controlled quantitative studies in the US have shown that teachers who hold leadership positions in the school (Kalogrides et al., 2012) and have more years of experience in a particular school (Grissom et al., 2015) are allocated to less challenging classes. Grissom et al. $(2015$, p2) argue that teacher who have worked "within the system" for longer accrue "social and organisational capital, including respect from school leaders and other actors, understanding of school organisational processes and relationships within the school community" which allow them to influence "decisions about how students are assigned to teachers". These findings provides a direct link between teacher experience and teacher assignment.

We can investigate this in our data by modelling how disadvantaged a teacher's target class is based on teacher and school characteristics. In Model 3 we regress the number of years a teacher has spent at their current school on how disadvantaged their target class is, controlling for school level factors (including proportion of FSM pupils in the school as a whole). We find that number of years since joining the school is associated with a $2 \%$ reduction in the odds of having a more disadvantaged class, significant at the $99 \%$ level. Again, this effect will compound over a multiple unit change in the predictor variable. In Model 4 we add individual level controls, including how many years of experience a teacher has in total. This leaves the coefficient almost unchanged but expands the standard error, which means the coefficient is no longer statistically significant. In Model 5 we restrict our sample to those teacher who said their target class was representative of their other classes, which reduces our sample size by around a third. The coefficient on Model 5 remains virtually unchanged but the standard errors expands further and the result is no longer statistically significant at conventional levels. Despite the failure of this robustness check, this evidence is broadly consistent with the findings from Grissom et al. (2015) that teachers who have spent longer in a school are better able to influence their allocation to less disadvantaged classrooms. 
$<$ Table 2 about Here >

\begin{tabular}{llccc}
\hline & & Model 1 & Model 2 & Model 3 \\
\hline & Odds ratio & $0.983^{* * *}$ & 0.984 & 0.987 \\
Years at current school & Standard error & $(0.00523)$ & $(0.00935)$ & $(0.01080)$ \\
& $\mathbf{9 5 \%}$ confidence interval & $0.973-0.993$ & $0.965-1.0022$ & $0.966-1.0083$ \\
& $\mathrm{~N}$ & 2,105 & 2,040 & 1,392 \\
\cline { 1 - 2 } School level controls & & $\checkmark$ & $\checkmark$ & $\checkmark$ \\
Teacher level controls & & & $\checkmark$ & $\checkmark$ \\
Only representative target classes & & & & $\checkmark$ \\
\hline
\end{tabular}

It is also possible that the allocation of less experienced teachers to more deprived classes reflects a strategic choice on the part of school leaders. In 2013, and to some extent now, schools were being held accountable for the proportion of pupils who achieve five or more $\mathrm{A}{ }^{*} \mathrm{C}$ grades. Deprived pupils also tend to be low attaining and many of the most deprived will therefore not be within range of the $\mathrm{C} / \mathrm{D}$ borderline. Schools therefore face less incentive to allocate experienced teachers to these classes and this may influence teacher allocation (Boyd et al., 2008).

\section{Policy Implications}

The policy imperative to do something about inequalities in the allocation of teachers to schools is particularly pressing at present. The current government is looking for ways to address teacher shortages, including expanding opportunities for teachers to train on the job and achieve qualified teacher status without necessarily completing an academic degree (Peacock, 2017). Disadvantaged schools facing staffing shortages may therefore find themselves making even greater use of non-specialist or unqualified teachers.

There are several policy options for changing the allocation of teachers between schools. One is to incentivise high-quality teachers to work in schools with more disadvantaged pupils. The Government are trying various approaches to this, including the recently announced student loan forgiveness for new teachers who teach in certain parts of the country (Schools Week, 2017). Figures 6 and 7 show how teacher pay varies by the deprivation level of a school. On average, teachers working at schools with more disadvantaged pupils are paid less. But this is because they tend to be less experienced. In order to disentangle these effects we regress teacher pay on deprivation level of the school. Then in regression 2 we add individual teacher characteristics, including experience, to show how otherwise identical teachers are paid across different levels of school deprivation. Next, we add regional dummies to take account of local labour market pay conditions. Finally, we replace the regional dummies with parliamentary constituency random effects so that we are identifying how pay varies by school deprivation for similarly experienced and qualified teachers working in nearby schools.

The results show that if a given primary teacher moved from a local school in the lowest to a school in the highest deprivation quintile they could expect to achieve a pay rise of around $£ 530$ per annum. A secondary teacher making the same move would currently gain $£ 1,289$ per annum. These incentives may already be supressing inequalities in teacher allocation. Indeed, an evaluation of a 
comparable annual retention bonus implemented in North Carolina found that it reduced turnover among targeted teachers by around $14 \%$ (Clotfelter et al., 2008). Further research is required to understand how much larger incentives in England would need to be to eliminate or reverse existing inequalities.

\section{$<$ Figure 8 about Here>}

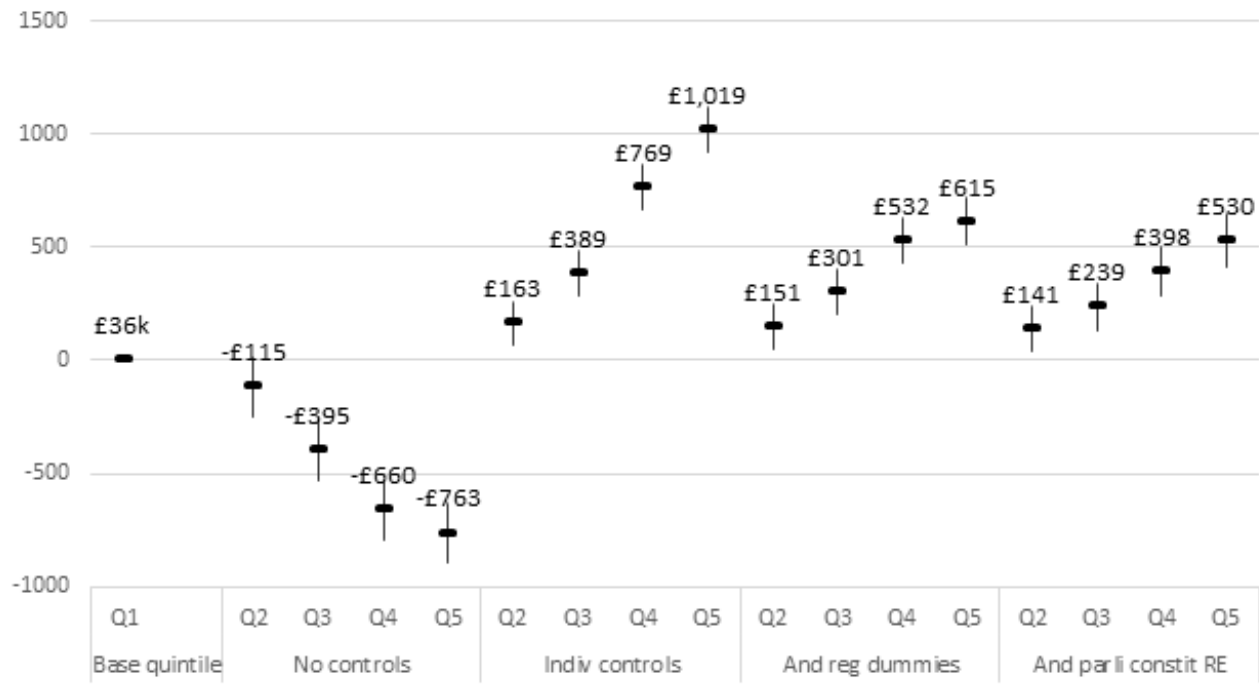

$<$ Figure 9 about Here>

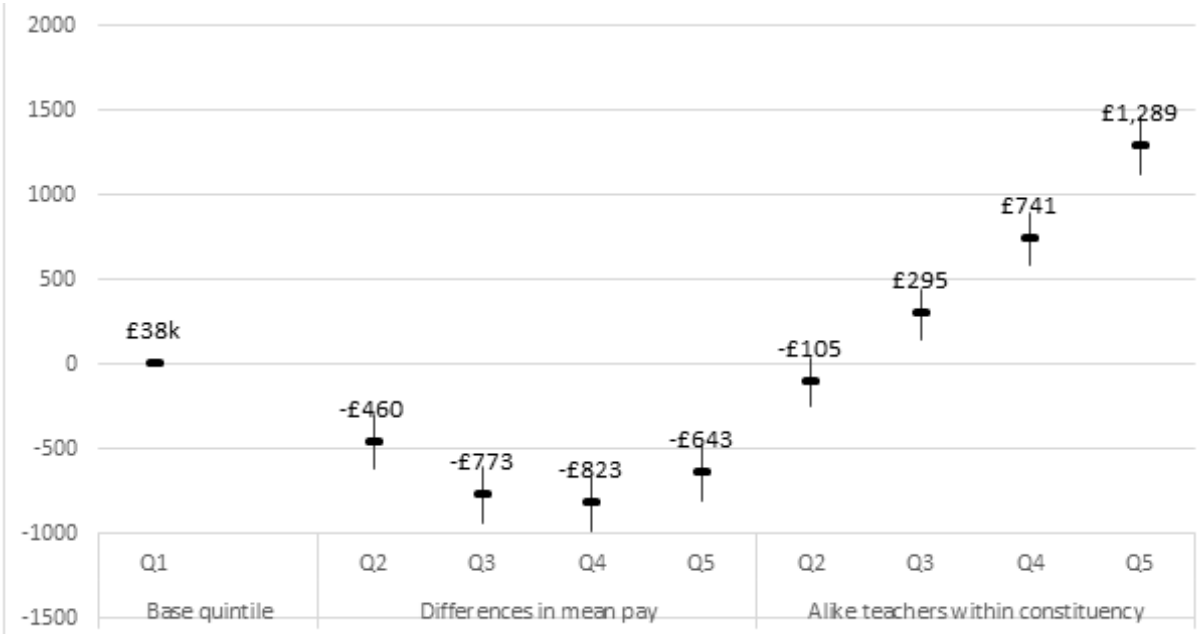

A second option for equalising between-school allocation is to improve working conditions for teachers, since this has been repeatedly linked with retention in controlled quantitative studies (Johnson et al., 2012; Sims, 2017). The Job Demands Resources (JDR) model (Demerouti et al., 2001) provides a useful framework for understanding the mechanism by which working conditions affect turnover. It states that when the demands placed on employees exceed the resources available to them (defined as anything that helps achieve their goals) over a sustained period, people become exhausted, disengage from their work and eventually leave. The model has been shown to empirically 
explain burnout and turnover across a range of professional settings, including teaching (Crawford $e t$ al., 2010; Hakanen et al., 2006). Perhaps the most promising way of providing additional resources (support) to young teachers is by providing high quality mentoring, which has been shown to reduce turnover in carefully controlled evaluations (Smith and Ingersoll, 2004; Rockoff, 2008). In terms of reducing demands on teachers, research shows that giving them simple, stable work assignments, rather than teaching multiple subjects or shifting year groups also reduces turnover (Donaldson and Johnson, 2010; Ost and Schiman, 2015). Ofsted (2017) have recently made a series of announcements which suggest they will pay closer attention to teacher turnover and working conditions when they inspect schools.

Changing the allocation of teachers within schools is perhaps more challenging, since this is determined by subtle political processes inside schools. One option is to incentivise schools to raise the academic achievement of more disadvantaged groups through the introduction of additional performance metrics for publication in school performance tables or for use by the school inspectorate. Evidence from the US suggests that performance metrics are able to influence the allocation of teachers within schools in this way (Boyd et al., 2008). Any such metrics would however require careful design in order to avoid unintended consequences.

\section{Conclusion}

We find clear, consistent evidence of an inequitable allocation of teacher quality between schools. This likely reflects both the preferences of inexperienced teachers to work in schools with disadvantaged intakes and, on the flip side, a greater supply of vacant positions in these schools, due to poor working conditions damaging staff turnover. This creates a cycle of entry and exit which has the effect of holding down average experience, pushing up turnover and creating recruitment pressures for schools which often leads to them hiring teachers with mismatched qualifications. Within schools we also find some evidence of inequitable allocation of more experienced teachers. This likely reflects the fact that more experienced teachers tend to have been in their current school for longer than their less experienced peers, which allows them to influence their allocation to less disadvantaged classrooms. Improving working conditions within disadvantaged school is likely to be a low cost way of disrupting the cycle of hiring, quits and further hiring of low quality teachers that is holding down average teacher quality in schools with disadvantaged intakes.

\section{References}

Aaronson, D., Barrow, L. and Sander, W. (2007), 'Teachers and student achievement in the Chicago public high schools', Journal of Labor Economics, 25:1, 95-135. 
Allen, R. (2017) Creating an indicator of the subject background of the teacher, A research note. Retrieved from: https://educationdatalab.org.uk/wp-content/uploads/2017/01/Annex-BCreating-an-indicator-of-the-subject-background-of-the-teacher.pdf

Allen, R., Parameshwaran, M. and Nye, P. (2016) The careers of Teach First Ambassadors who remain in teaching: job choices, promotion and school quality. Report to Teach First by Education Datalab.

Allen, R., Burgess, S. and Mayo, J. (2012), 'The teacher labour market, teacher turnover and disadvantaged schools: new evidence for England', Education Economics, http://dx.doi.org/10.1080/09645292.2017.1366425.

Avvisati, F., and Keslair, F. (2015), REPEST: Stata module to run estimations with weighted replicate samples and plausible values. Statistical Software Components.

Baird, M., Engberg, J., Hunter, G. and Master, B. (2016), Improving Teaching Effectiveness: access to effective teaching. RAND Corporation and American Institute for Research.

Baumert, J., Kunter, M., Blum, W., Brunner, M., Voss, M., Jordan, A., Klusmann, A., Krauss, S., Neubrand, M. and Tsai, Y. (2010), 'Teachers' mathematical knowledge, cognitive activation in the classroom, and student progress', American Educational Research Journal, 47:1, 133-80.

Blanden, J. and Macmillan, L. (2014), Education and Intergenerational Mobility: Help or Hindrance? Department of Quantitative Social Science Working Paper No. 14-01.

Boyd, D., Lankford, H., Loeb, S., and Wyckoff, J. (2008), The Impact of Assessment and Accountability on Teacher Recruitment and Retention: Are There Unintended Consequences?, Public Finance Review, 36:1, 88-111.

Boyd, D., Lankford, H., Loeb, S., Rockoff, J. and Wyckoff, J. (2008), The narrowing gap in New York City teacher qualifications and its implications for student achievement in high-poverty schools', Journal of Policy Analysis and Management, 27:4, 793-18.

Burgess, S. (2015), Human Capital and Education: The State of the Art in the Economics of Education. COEURE: Cooperation on European Research in Economics.

Chetty, Raj, John N. Friedman and Jonah E. Rockoff. (2014), 'Measuring the impacts of teachers II: Teacher value-added and student outcomes in adulthood', The American Economic Review, 104:9, 2633-79.

Chingos, M. M., \& Peterson, P. E. (2011), 'It's easier to pick a good teacher than to train one: familiar and new results on the correlates of teacher effectiveness', Economics of Education Review, 30:3, 449-65.

Clotfelter, C., Ladd, H. F., Vigdor, J. L. and Wheeler, J. (2006), 'High-poverty schools and the distribution of teachers and principals', North Carolina Law Review, 85, 1345-79.

Clotfelter, C. T., Ladd, H. F. and Vigdor, J. L. (2006), 'Teacher-student matching and the assessment of teacher effectiveness', Journal of human Resources, 41:4, 778-820.

Clotfelter, C. T., Ladd, H. F. and Vigdor, J. L. (2007), 'Teacher credentials and student achievement: Longitudinal analysis with student fixed effects', Economics of Education Review, 26:6, 673682. 
Clotfelter, C., Glennie, E., Ladd, H. and Vigdor, J. (2008), 'Would higher salaries keep teachers in high-poverty schools? Evidence from a policy intervention in North Carolina', Journal of Public Economics, 92, 1352-70.

Crawford, E. R, Lepine, J. A. and Bruce, L. R. (2010), 'Linking Job Demands and Resources to Employee Engagement and Burnout: A Theoretical Extension and Meta-Analytic Test', 95:5, 834-48.

Croninger, R. G., Rice, J. K., Rathbun, A. and Nishio, M. (2007), 'Teacher qualifications and early learning: Effects of certification, degree, and experience on first-grade student achievement', Economics of Education Review, 26:3, 312-24.

Demerouti, E., Bakker, A. B., Nachreiner, F. and Schaufeli, W. B. (2001), 'The job demandsresources model of burnout', Journal of Applied psychology, 86:3, 499-512.

Donaldson, M. L. and Johnson, S. M. (2010), 'The price of misassignment : the role of teaching assignments in Teach for America teachers' exit from low-income schools and the teaching profession. Educational Evaluation and Policy Analysis, 32:2, 299-323.

Feng, L. (2010), 'Hire today, gone tomorrow: New teacher classroom assignments and teacher mobility', Education Finance and Policy, 5:3, 278-316.

Feng, L., \& Sass, T. (2011), Teacher Quality and Teacher Mobility. CALDER Working Paper No. 57.

Finley, M. K. (1984), 'Teachers and tracking in a comprehensive high school', Sociology of Education, 57, 233-43.

Goe, L. (2007). The link between teacher quality and student outcomes: A research synthesis. National Comprehensive Center for Teacher Quality.

Goldhaber, D. D. (2007). Everyone's doing it, but what does teacher testing tell us about teacher effectiveness? Journal of Human Resources, 42(4), 765-794.

Goldhaber, D., Gross, B., \& Player, D. (2010), Teacher career paths, teacher quality, and persistence in the classroom: Are public schools keeping their best? Journal of Policy Analysis and Management, 30:1, 57-87.

Goldhaber, D. D. and Brewer, D. J. (2000), 'Does teacher certification matter? High school teacher certification status and student achievement', Educational Evaluation and Policy Analysis, 22:2, 129-145.

Grissom, J. A., Kalogrides, D. and Loeb, S. (2015), 'the micro-politics of educational inequality: the case of teacher-student assignments', Peabody Journal of Education, 90:5, 601-14.

Hakanen, J. J., Bakker, A. B. and Schaufeli, W. B. (2006), 'Burnout and work engagement among teachers', Journal of School Psychology, 43, 495-513.

Hanushek, E., \& Rivkin, S. (2010), Constrained job matching: Does teacher job search harm disadvantaged urban schools?, CALDER Working Paper No. 42.

Hanushek, E. and Rivkin, S. (2012), The Distribution of Teacher Quality and Implications for Policy, Annual Review of Economics, 4:1, 131-157. 
Harris, D. N. and Sass, T. R. (2011), 'Teacher training, teacher quality and student achievement', Journal of Public Economics, 95, 798-12.

Henry, G. T., Bastian, K. C. and Fortner, C. K. (2011), 'Stayers and leavers: early-career teacher effectiveness and attrition', Educational Researcher, 40:6, 271-80.

Hill, H., Charalambous, C. and Chin, M. (2015). Teacher characteristics and student learning: $a$ comprehensive assessment. Mimeo. Harvard Graduate School of Education.

Hobbs, G. (2016), 'Explaining social class inequalities in educational achievement in the UK: quantifying the contribution of social class differences in school 'effectiveness', Oxford Review of Education, 42:1, 16-35.

Hobbs, G. and Vignoles, A. (2010), 'Is children's free school meal 'eligibility' a good proxy for family income?', British Educational Research Journal, 36:4, 673-90.

Isenberg, E., Max, J., Gleason, P., Potamites, L., Santillano, R., Hock, H., \& Hansen, M. (2013), 'Access to effective teaching for disadvantaged students', Institute of Education Sciences.

Jerrim, J. (2012), 'The socio-economic gradient in teenagers' reading skills: how does england compare with other countries?', Fiscal Studies, 33:2, 159-84.

Johnson, S. M. and Birkeland. S. E. (2003), 'Pursuing a 'sense of success': new teachers explain their career decisions', American Educational Research Journal, 40:3, 581-617.

Johnson, S. M., Kraft, M. A. and Papay, J. P. (2012), 'How context matters in high-need schools: The effects of teachers' working conditions on their professional satisfaction and their students' achievement', Teachers College Record, 114:10, 1-39.

Kalogrides, D., Loeb, S. and Beteille, T. (2012), 'Systematic Sorting : Teacher Characteristics and Class Assignments’, Sociology of Education, 86:2, 103-23.

Kane, T. J., Rockoff, J. E. and Staiger, D. O. (2008), 'What does certification tell us about teacher effectiveness? Evidence from New York City', Economics of Education Review, 27:6, 615-631.

Kane, T.J., McCaffrey, D.F., Miller, T. and Staiger, O. (2013). Have We Identified Effective Teachers? Validating Measures of Effective Teaching Using Random Assignment. MET Project Research Paper: Bill and Melinda Gates Foundation.

Klassen, R. M. and Chiu, M. M. (2011), 'The occupational commitment and intention to quit of practicing and preservice teachers: Influence of self-efficacy, job stress, and teaching context', Contemporary Educational Psychology, 36:2, 114-29.

Loeb, S., Kalogrides, D. and Béteille, T. (2012), 'Effective Schools: Teacher Hiring, Assignment, Development, and Retention', Education Finance and Policy, 7, 269-304.

Lupton, R. and Thomson, S. (2015), The Coalition's Record on Schools: Policy, Spending and Outcomes. Social Policy in a Cold Climate Working Paper 13.

Machin, S., McNally, S. and Wyness, G. (2013), Educational attainment across the UK nations: performance, inequality and evidence. Educational Research, 55:2, 139-164. 
Macmillan, L. and Gregg, P. (2010), 'Family income and education in the next generation: Exploring income gradients in education for current cohorts of youth', Longitudinal and Life Course Studies, 1:3, 259-280.

McCaffrey, D.F., Sass, T.R., Lockwood, J.R. and Mihaly, K. (2009) The Intertemporal Variability of Teacher Effect Estimates, Education Finance and Policy, 4(4), 572-606.

McNatt, D. B. and Judge, T. A. (2008), 'Self-efficacy intervention, job attitudes, and turnover: A field experiment with employees in role transition', Human Relations, 61, 783-810.

Menzies, L., Parameshwaran, M., Trethewey, A., Shaw, B., Baars, S. and Chiong, C. (2015), 'Why Teach?', LKMCo.

Micklewright, J., Jerrim, J., Vignoles, A., Jenkins, A., Allen, R., Ilie, S., Bellarbre, E. and Hein, C. (2014), 'Teachers in England's Secondary Schools : Evidence from TALIS', Department for Education.

Monk, D. H. (1987), 'Assigning elementary pupils to their teachers', The Elementary School Journal, 88:2, 167-87.

NAO (2016), 'Training new teachers', Report by the comptroller and auditor general.

OECD (2012), Equity and Quality in Education: Supporting Disadvantaged Students and Schools, OECD Publishing.

OECD (2014), TALIS 2013 Results: An International Perspective on Teaching and Learning, OECD Publishing.

Ofsted (2017) Ofsted strategy 2017-22. Report retrieved from: https://www.gov.uk/government/uploads/system/uploads/attachment_data/file/648212/Ofsted_st rategy_2017-22.pdf

Ost, B. and Schiman, J. C. (2015), 'Grade-specific experience, grade reassignments, and teacher turnover', Economics of Education Review, 46, 112-26.

Papay, J. P. and Kraft, M. A. (2015), 'Productivity returns to experience in the teacher labor market: Methodological challenges and new evidence on long-term career improvement', Journal of Public Economics, 130, 105-119.

Peacock (2017) Routes into teaching and routes within teaching: the Chartered College perspective. Article retrieved from: https://chartered.college/routes-into-teaching

Perera, N., Treadaway, M. and Johnes, R. (2016), Education in England: progress and goals, Centre Forum.

Rockoff, J. E. (2008), 'Does mentoring reduce turnover and improve skills of new employees? Evidence from teachers in New York City', National Bureau of Economic Research Working Paper No. 13868.

Sass, T., Hannaway, J., Xu, Z., Figlio, D., \& Feng, L. (2010), 'VAM of Teachers in High-Poverty Schools and Lower-Poverty Schools', CALDER Working Paper 52. 
Schools Week (2017, $1^{\text {st }}$ Oct) Teachers to get student loan forgiveness in government pilot, Schools Week. Retrived from: https://schoolsweek.co.uk/teachers-to-get-student-loan-forgiveness-ingovernment-pilot/

Simon, N. S. and Johnson, S. M. (2013), 'Teacher turnover in high-poverty schools: what we know and can do', Project on the Next Generation of Teachers Working Paper.

Sims, S. (2017) TALIS 2013: Working Conditions, Teacher Job Satisfaction and Retention. London: Department for Education Statistical Working Paper.

Slater, H., Davies, N. M. and Burgess, S. (2012), 'Do teachers matter? Measuring the variation in teacher effectiveness in England', Oxford Bulletin of Economics and Statistics, 74:5, 629-45.

Smith, T. M. and Ingersoll, R. M. (2004), 'What are the effects of induction and mentoring on beginning teacher turnover?' Educational Evaluation and Policy Analysis, 26:3, 681-714.

Smithers, A. and Robinson, P. (2000), 'Coping with teacher shortages: report for the national union of teachers', Centre for Education and Employment Research.

Strand, S. (2014), 'School effects and ethnic, gender and socio-economic gaps in educational achievement at age 11.' Oxford Review of Education 40:2, 223-245.

Thrupp, M. and Lupton R. (2006) Taking School Contexts More Seriously: The Social Justice Challenge, British Journal of Educational Studies, 54 (3), pp. 308-328Wayne, A. and Youngs. P. (2003), 'Teacher characteristics and student achievement gains: A review', Review of Educational Research, 73:1, 89-122.

Wiliam, D. (2016), Leadership for Teacher Learning. Learning Sciences International.

Wiswall, M. (2013), 'The dynamics of teacher quality', Journal of Public Economics, 100, 61-78.

\section{Appendix}

In Figure 4 and Figure 5, we model the probability that a teacher (i) leaves their school (j) at the end of the 2012/13 academic year using a series of logistic regressions with the overall form:

$\log \left(\frac{\operatorname{Pr}(\text { leave })}{1-\operatorname{Pr}(\text { leave })}\right)_{i j}=\beta_{0}+\beta_{1} \cdot F S M_{j}+\beta_{2} \cdot \operatorname{Dem}_{i j}+\beta_{3} \cdot \operatorname{Reg}_{j}+\varepsilon_{i j}$

Where:

$\operatorname{Pr}($ leave $)=$ The probability of leaving a school at the end of the year

$F S M=$ A categorical variable ranging from one (schools in the lowest quintile of pupils with free school meals status) to five (the highest quintile). 
Dem $=$ A vector of individual teacher characteristics: age in years, a dummy indicting female gender, a dummy indicating ethnic minority status, a dummy indicating qualified teacher status, and number of years since qualification.

$\operatorname{Reg}=\mathrm{A}$ vector of regional dummies that are included as fixed effect dummies. In the right hand panel of Figure 4 and Figure 5, we replace this vector of region dummies with a larger number of parliamentary constituency indicators (PCReg), which we model as a random effect: $\mathrm{PCReg}_{j} \sim N\left(0, \sigma_{\mathrm{PCReg}}^{2}\right) \quad, \quad \varepsilon_{i j} \sim N\left(0, \sigma_{\varepsilon}^{2}\right)$ 